Western Washington University Western CEDAR

$7-1-2012$

\title{
Implementing Reference Statistics Collection Software at Multiple Library Service Points
}

\author{
J. Gabe Gossett \\ Western Washington University, gabe.gossett@wwu.edu \\ Elizabeth Stephan \\ Western Washington University, elizabeth.stephan@wwu.edu \\ Rebecca M. Marrall \\ Western Washington University, rebecca.marrall@wwu.edu
}

Follow this and additional works at: https://cedar.wwu.edu/library_facpubs

Part of the Library and Information Science Commons

\section{Recommended Citation}

Gossett, J. G., Stephen, E., Marrall, R. (2012). Implementing reference statistics collection software at multiple library service points [peer-reviewed article]. New Library World, 113(5/6). doi:10.1108/03074801211226328

This Article is brought to you for free and open access by the Western Libraries and the Learning Commons at Western CEDAR. It has been accepted for inclusion in Western Libraries Faculty and Staff Publications by an authorized administrator of Western CEDAR. For more information, please contact westerncedar@wwu.edu. 


\section{Literature Review}

Libraries have been collecting statistics on the questions they answer for more than a century, yet most of the literature on this topic does not focus on how statistics collection was implemented. The library literature reflects that there have been numerous approaches to recording statistics, but the literature tends to focus on topics such as the type of information collected and the data analyses of collected statistics rather than how statistics collection procedures were implemented. What is clear, however, is that there has not been one approach that worked for, or has been adopted by, the majority of libraries. As Krikelas (1966) points out there are three reasons why libraries collect statistics: to support administrative decisions, describe library activities, and "to establish general principles and relationships concerning library organizations, administration, and use" (p. 494). He also notes that it has been difficult for libraries to develop uniform terms and categories. As Rothstein (1964) points out, it has been a topic debated for decades.

While Western Libraries was seeking to implement a reference statistics collection scheme for multiple service points this issue was not well-addressed in the library literature. Novotny's survey of ARL libraries reference statistics collection and assessments indicates that "at least $60 \%$ routinely gather transaction data not only for questions asked at a reference desk, but also for telephone inquiries, e-mail reference questions, individual appointments, [and] questions asked at other service points (e.g., circulation, media desk) (2002, p. 10)." Despite this there appears to be little scholarship examining implementation of reference data collection at service points that are not within a reference department.

Beginning in 1976 there was regular discussions within American Library Association concerning the issue of using more consistent terms and categories for reference data collection. Forms for reference statistics were developed, reworked, and ultimately dismissed because they did not suit the needs of a library. Uniform headings and terms came under regular criticism because of the "meaninglessness of the statistics reported, inadequacy of the data, ambiguities of the categories, and the internal inconsistencies of the published data" (Krikelas, 1966, p. 496). As of 2002, Novotny reported in a study of ARL libraries that there was still little consensus on how reference statistics should be recorded. Logan argues that measuring reference duties has changed over time from assessing quality to justifying the need for reference services, and concludes that each institution should develop their own individualized assessment methodology that creates a holistic perspective of reference services (Logan, 2009, p. 231). Data recorded for reference interactions is often very specific to an institution and what a library wants to know about the services they are providing (Murgai, 2006).

Despite the lack of consensus there has been progress made in developing conceptual framework for the terms and categories that might be used for gathering reference statistics. The Warner system was developed by Deborah Warner (2002), a director of a health sciences library, after conducting a literature review of how other libraries recorded reference statistics. Warner worked with colleagues to develop a system in which queries were categorized by complexity. The categories included were: nonresourcebased, skill-based, strategy-based, and consultation. The system is more than a decade old and still helpful for contemporary library personnel struggling to define reference duties, and subsequently, how to record statistics for them (Henry \& Neville, 2008; Meserve et al., 2009). The Warner system has also been tested against the Katz system, another method for categorizing reference statistics. In one study two librarians coded past reference interactions in order to examine the best ways to record reference queries and found 
fewer discrepancies when using the Warner system (18\%) versus the Katz system (61\%) (Henry \& Neville, 2008).

Other institutions' experiences with developing reference tracking terms and categories that were implemented using an online system are represented in the literature. Aguilar, Keating, and Swanback (2010) provide an overview of how they dealt with common problems associated with recording reference statistics — definitions, method of recording, and time absorbed by recording — at the Zimmerman Library at the University of New Mexico. Based on a self-analysis white paper, the Zimmerman Library eventually decided to create a database where personnel could enter data. Implementation of this database let multiple service points discuss definitional issues (i.e., reference vs. directional), and provided useful information for collection development purposes. The Aguilar et al. experience demonstrated how to generate a library-wide discussion about statistics collection that subsequently informed their choices for specific data collection terms. Texas A\&M University Libraries went through a similar process as well (Smith, 2006) before building a Web-based statistics collection interface. They based their statistics collection on ARL standards, but then through discussion also decided to exceed those standards by including directional and technical questions to support their signage and systems support efforts.

Technology has had a major impact on collecting reference statistics. Moving from a paper-and-pencil statistics collection process to electronic methods gives institutions a chance to review the type of information they want to collect and think critically about how they want to go about doing so. As early as 1984 a company called Microdex was marketing a customizable software program called Create that ran on Apple II and Apple DOS computers (Smith, 1984). The program allowed libraries to input statistics based on a number of variables, such as day of the week, time, type of question, duration, subject, and more. In a more current example, the University of Queensland developed LibStats, an open source application that could be used across multiple locations (Jordan, 2008). Prior to developing, implementing, and using LibStats, the University of Queensland was using an Excel spreadsheet to record transactions. While developing LibStats a group made up of representatives from all sections of the University of Queensland library was established and asked several questions: "What are we counting? What are we not counting? What should we count? What is happening in the branches? What needs clarification? What confusions or inconsistencies are there?" (pp. 19-20). Prior to this, Queensland was not being efficient in how statistics were collected because everything was counted, all "inputs and outputs" (p. 19). When LibStats was eventually implemented, the project manager served as the main contact person so that there could be consistency in using the software over multiple locations.

Similar to Queensland, Helmke Library at Indiana University-Purdue University Fort Wayne transitioned from gathering statistics on paper to an online Web form powered by MySQL database (Garrison, 2010). Helmke Library had moved to a two-tier reference system that made use of consultations and referrals, and a more sophisticated statistics system was needed. An online form better fit their needs. After using an online system, "statistical reports became immediately accessible, librarians demonstrated greater responsibility for accurate recording and found more uses for reference statistics than had been originally anticipated" (Garrison, 2010, p. 209).

Statistics collection in many university libraries is also impacted by the increasing forms of technology used for providing reference services, including online chat, phone, and text messaging (Novotney, 2002). 
In their analysis of the Warner and Katz query collection methods Henry and Neville (2008) conclude that traditional forms of reference tracking do not work as well as they once did because of developments in technology related to reference services. On the other hand, Logan, in a historical overview of efforts to evaluate reference services from late nineteenth century to contemporary times, contends that while reference technology has certainly changed, the primary duties of reference librarians have not (Logan, 2009). Each branch was able to see their own activity and statistics and all staff are able to see the reports, which gives staff a sense of involvement in their branch's contribution to the library's overall mission.

\section{Why LibAnswers?}

Western Libraries (http://library.wwu.edu) is part of Western Washington University, a comprehensive regional Masters-granting university with a student population of approximately 15,000 students. The Libraries are made up of the main library, the Map Library, the Music Library, and Heritage Resources (Special Collections, University Archives, and the Center for the Pacific Northwest). The main library has several service points, including the Reference and Instruction Desk, the main Circulation Desk, and the Media Desk. Special Collections is located in the main library, while the University Archives and the Center for the Pacific Northwest Studies are located in the Goltz-Murray Building. In 2010, the Writing Center, the Teaching and Learning Academy, and Writing and Instructional Support became part of the library, adding three more unique service points to the Libraries. During the twelve month period ending in August 2011, the main library had a monthly average gate count of just over 100,000. Prior to 2010 the majority of service points in the library were tracking public service interactions with LibStats, an opensource reference tracking software, or using some method of their own.

In early 2010, Western Libraries staff began to look for more stable replacements for LibStats. LibStats was developed by University of Queensland in Australia and was still available, but development has slowed and its functions were fairly minimal. At the same time there was a push to find a way to incorporate text messaging, Twitter, and other forms of virtual communication into reference services. Springshare's LibAnswers provided both statistics tracking and analytics tools that would allow data to be scrutinized on a highly granular or meta level as well as a public interface for staff and librarians to answer questions via email, text, and Twitter. Because of the Libraries' work with Springshare's LibGuides we were familiar with the company's ongoing development and technical support.

Moving from one statistics software to another meant there would be trade-offs. LibStats allowed each service point to develop a set of unique terms and question types, but when LibAnswers was first introduced it only had the option for one shared interface. This meant that using LibAnswers would require the development of a shared list of categories and terms that all service points in the Libraries would use. Western Libraries accepted this trade-off because of the enhanced virtual reference and statistics analysis tools that would come with LibAnswers. A task force of individuals from across the Libraries met to develop a set of terms and categories for the new system. Initially, this included representatives from Instruction and Research Services (IRS), Circulation, the Writing Center, and the Map Library, and eventually grew to include Heritage Resources, Writing and Instructional Support (WIS), the Teaching and Learning Academy (TLA), and the Music Library. Over the course of a fall quarter the task force developed a set of terms and categories that could be used to collect statistics across multiple desks with similar yet different functions and users. Two of the coauthors, Gossett and Stephan were on the initial task force, with Gossett leading the overall effort. After the task force was finished time was set aside to solicit comments from others within the Libraries on the chosen categories and terms, which gave everyone time to get acquainted with the language being used and get buy-in from the personnel it would be impacting. After that process was completed the three coauthors developed training materials and lead training sessions for the service desks. 


\section{How Do We Categorize What We Do?}

The task force collected and compiled a master list of categories and terms that were being used at all of the Libraries' service points for patron questions. Typically, service points had been collecting statistics in five categories and continued to wish to do so: the location where the question answered, patron type, type of question (i.e., directional, instruction, patron record, etc.), length of time spent on each question, and the mode of access (in-person, phone, chat, etc.). Where each location differed from each other most was in the types of terms they were using within the above categories. Each service point was asked to look at how they had been using the categories and terms and eliminate any that had become obsolete, were duplicated, or clearly had little use. The remaining categories and terms were then used for discussion to create a combined set. Most of the task force's time was spent on developing a list of terms related to the type of question asked and types of patrons. Several short meetings between Gossett and heads from the service points help lay the groundwork for a larger group discussion, out of which came a proposed set of categories and terms that was posted on the Libraries' Intranet for comment. See Appendix 1 for the initial combined terms and categories.

Due to the nature of their work many service points had different interests in the type of information they wanted to record. There was also a desire to implement the simplest set of categories and terms without losing valuable information. Meanwhile, it was important to make clear the benefits and technical limitations of the LibAnswers software so that there would be an appreciation of how to best proceed. To help keep the divergent needs focused it was important to keep meetings organized around the question, "What do we really want to know?" Keeping the focus on this question helped in two ways: It kept the discussion of terms and categories from getting too far off track so that extraneous discussions could be avoided, and it allowed the task force to focus on developing the simplest set of language possible that could be used for collecting statistics.

During discussions it became clear that different service points used terms in very different ways, often reflecting the types of services they provided. Staff at the Circulation Desk, for example, marked a question type as "instruction" when a member of their staff showed a user how to search for reserves, read a call number, or access their library account. They used the term "reference" in two different ways: When the Reference Desk was closed, a question was tagged as "reference" when circulation staff showed a user how to complete a search or gave research advice-basically, when they did things normally done by IRS staff and librarians. When the Reference Desk was open, circulation staff tagged an interaction as "reference" when a user was referred to the Reference Desk. IRS' roughly equivalent terms to the ones noted above used in Circulation were "reference transaction" and "directional." An ongoing issue in IRS was that librarians used these terms differently. One IRS staff member might consider almost all of the questions they answer to be reference interactions, including how to find books or articles, while another staffer might consider those same activities directional transactions. Furthermore, while Circulation used a term for questions related to reserves, Reference did not since those questions would typically be counted as reference interactions or directional questions. What this meant was that there was data collection inconsistency that made the Libraries' statistics collection efforts less useful than they could be. Changing to the LibAnswers single interface pushed the Libraries' staff to think through which words best reflected the nature of public services that were being provided.

Many of the changes to terms were not difficult. For instance, with the above examples it became clear that the distinction that needed to be made was whether questions were directional and informational in nature or instructional. The term "instruction" made sense to replace what IRS had been calling reference 
interactions because the department was interested in demonstrating how reference services related to the instructional mission of the university. It was agreed that in any instance where a staff member was showing a patron how to do something the question would be labelled as instruction. Other questions, such as where is the copier, could easily be labelled as "directional/info." At one point it was discussed whether there was even a need to use different terms for directional or informational questions and instructional ones since the length of the interaction might be just as good an indicator of whether a question was instructional or not. Statistics collected in the past hinted that instructional questions tended to take more time and basic directional and informational questions usually took less than 2 minutes. Ultimately, it was decided that both terms would be kept.

Although the actual question was not asked until training, an undertone to many of the task force meetings was whether the library was using these statistics to justify its existence. Western Libraries was going through the second of two back-to-back budget cuts. This type of concern is natural and it is not a bad question to ask for any library restructuring its method for gathering statistics. Would these statistics be used to justify the existence of a service desk? Yes and no. Ultimately, the statistics would be used to track trends in use and to see the types of questions being asked. Statistics could also be used to make staffing decisions at the desk. The question not being asked was whether the results would be used to cut positions. As far as the task force knew, this was not the intention of tracking usage statistics. However, the statistics would be used in the Libraries annual report to the university administration.

\section{The Exception to Every Rule}

The first step in moving towards a common interface was to better understand how the different service points used the statistics. Since 2008 several other areas of the university have become integrated into the library. The Center for Pacific Northwest Studies (CPNWS) and University Archives were administratively consolidated with the Libraries in 2008. When they joined the Libraries they became part of Heritage Resources, which also included Special Collections. The CPNWS and the Archives are located in a building on the far south end of campus while Special Collections is housed in the main library building. The main challenge to accommodating the needs of Heritage Resources was that they recorded much more detailed statistics than other departments.

The CPNWS is an archives that serves the overall western Washington community by collecting, processing, and making available archival collections relating to local history. While all of the Libraries facilities are open to the general public, the CPNWS works more heavily with local researchers, ranging from high school students to genealogists. When using LibStats they broke down their patron and question types categories into to very specific terms and wished to continue to do so. In contrast to this other departments wanted to keep smaller lists for terms for their patron and question type categories. After discussing the issue in a series of meetings and email exchanges it was decided that the Libraries would take advantage of the fact that LibAnswers does not require a selection be made in every category. Specialized categories for patron and question type were created for Heritage Resources that everyone else would simply ignore. This same method was used for the Map Library as well so that they could collect statistics on the types of collections being used. See Appendix 2 for the set of categories and terms that were implemented.

The Writing Center, Writing and Instructional Services (WIS), and the Teaching and Learning Academy (TLA) moved into the main library in 2010. Initially, the Writing Center, WIS, and TLA were going to become part of the move to LibAnswers and participated in early discussions to come up with a common 
set of terms and categories. However, because their services were significantly different from those offered by other service desks, LibAnswers could at most only be a partial solution for them. The Writing Center came to use LibAnswers to record basic statistics for the services it was providing but also maintained another database with more detailed information, including running logs of the work they were doing with individual students. WIS and TLA have still not fully implemented use of LibAnswers and it is not clear that it will work for them. They would like to have more data on the services they provide, but because they typically provide their services through events, LibAnswers is not necessarily a useful tool. When Springshare released a version of LibAnswers that was customizable to individual department's needs the Writing Center was able to use it more effectively.

While every service point attempted to make the original version of LibAnswers work for them, it wasn't always possible. Despite that, one thing all members got out of the exercise was a better understanding of what other areas of the library did. The task force work and training workshops allowed us to work towards a common language and develop a sense of organizational cohesion that was unexpected. It also set the stage for a more thorough implementation of LibAnswers once the multiple interface version was introduced in early 2011.

\section{Training}

With consistent data collection as a goal, training library personnel was a crucial step in implementation of the software. Initially it was not clear how to best train personnel from diverse service points with widely varying schedules. There were, at a minimum, thirty-four staff and librarians who needed to be trained on the software, in addition to numerous student employees. Because different service points had different concerns and uses about LibAnswers, it became clear that a one-size-fits-all internal training would not meet everyone's needs. Flexibility was key in delivering relevant workshops.

In order to be flexible, three librarians-who are also the co-authors of this article-developed the training sessions and material. The goal was to have at least two of the three trainers at each session. This allowed for one person to handle the demonstration of LibAnswers while the other explained how to use it and answered questions. For larger groups, all three trainers were present, and for smaller groups only one was needed. In some cases one-on-one training was offered to meet scheduling needs. It was made clear to everyone using the system, whether they came to a training session or not, that the three trainers were available for questions and informal training as needed outside of the workshops.

The trainers also set up an instructional website to accompany the LibAnswers workshops using LibGuides. See Appendix 3 for a screenshot from the training LibGuide. This page included pictures of the new interface and step-by-step instructions for entering and editing transactions. Short video tutorials using Jing were also included. Much of the training was scheduled during the break between fall and winter quarters. A Google survey eform was embedded in the website allowing people to sign up for the session that best fit their schedule. While the initial plan was not to focus training sessions by department, in many cases that is what happened. Each session ended up being customized to meet the specific needs of the personnel attending the workshop. 
There were pros and cons to having more department-specific training sessions. A workshop could focus more directly on a department's specific needs in using the LibAnswers, but it also risked getting derailed with questions about how the data was going to be compared with other departments. Training with individuals from multiple departments and service desks, on the other hand, allowed for a broader understanding of what each department did. Like the discussions during the initial task force phase, these training sessions provided an opportunity for some unexpected but appreciated organizational development.

While the workshops adapted to meet the needs of those attending a specific session, a common theme emerged: How to balance the new data collection method without impacting work-flow. Service points at most academic libraries experience patterns of increased and decreased activity during specific parts of the school term. Many personnel—especially from the Reference and Circulation-expressed concern about the ability to enter accurate data because the LibAnswers interface looked much more complicated than the LibStats interface. Some of this was due to the Springshare design, some of this was due to the complexity of our own terms and categories. The three trainers were part of IRS and had been using LibAnswers during the initial trial period. This experience was key to temper concerns that the new seemingly more complex interface would cause work-flow problems.

During one session made up of primarily staff from Circulation, these concerns about work-flow came to the forefront. The Circulation Desks are the busiest service points in the Libraries because they provide a wide variety of services, including checking in and out materials and equipment, handling patron accounts, and managing reserves, besides also being the most common service points for directional assistance. Staffed by both full-time personnel and students, the Head of Circulation was concerned that LibAnswers would disrupt the system they had developed while using LibStats. Demonstrating the software's ease of use and giving personnel the chance to use it hands-on helped allay these fears.

\section{Where are we now?}

During the initial test period and the library-wide implementation of LibAnswers, Gossett worked with the Libraries' IT Department to provide product development feedback to Springshare. The need for multiple interfaces for multiple service points was one of the first and, and most major, suggestions implemented by Springshare. This took place a few months after the workshops in the library and very little additional training and support was required in order to get staff to adapted to the application update. Having multiple interfaces allowed each public service desk to customize their input screens. It also allowed some departments in the Libraries to fully adapt LibAnswers which had not been able to before. To date only Writing Instruction Support and the Teaching and Learning Academy departments have not moved to LibAnswers, but discussions are ongoing about how to include their services as well.

When all desks were using the same interface it was easy for everyone logged in to see the types of questions received at each desk. Librarians at the Reference Desk could see the types of research questions being asked at the Circulation Desk and the staff at the Circulation Desk could, in turn, see how many questions about patron records were asked at Reference. It also allowed each department to get a better idea of the question volume at all service points. This was, once again, an opportunity to better understand what happens at different public service desks. However, having individual and customizable interfaces for each service desk made tracking statistics easier in the long run and outweighed the advantages of using a single interface. Anyone logged into LibAnswers can toggle between the screens for different service desks and can still see the types of questions asked, but it takes a little more effort. 
After the switch to multiple interfaces, most departments immediately customized their interfaces to better fit their needs. Despite this, going through the process of developing a standardized set of terms and categories was not in vain. What was not expected during this process was the organizational development opportunities that came out during the initial discussion and training sessions. There was also greater consistency in term usage between departments than before, allowing us to better compare the services provided. Ultimately, the process of discussing and working towards some consensus on the terms and categories used to record transactions with our patrons has been almost as useful as the outcomes that are in place today.

Western Libraries has been using LibAnswers since the summer of 2010 and most involved are happy with the switch. The advanced analysis tools and ability to reach patrons in new ways are of great use. LibAnswers has a public knowledgebase component that has been useful as a way to allow patrons to find answers to their questions on their own. When librarians or staff record an interaction with a patron there is an option to make the questions and answers public. As of the writing of this article Western Libraries had public answers to 428 questions, which can be browsed at this URL: http://askus.library.wwu.edu/. In some cases the questions and answers have been viewed hundreds of times. When the public knowledgebase is searched by a user, the user is provided with a list of questions that meet their search. If they decide that none of the questions match their own they have the option to submit their question through a Web form. While IRS has not completely eliminated email reference, this interface has largely taken its place. It allows questions and answers to be picked up, referred, and answered by multiple librarians instead of having all email questions going to one person. Using a similar interface LibAnswers can be used to answer questions via Twitter and text message. The public knowledgebase wasn't the main reason Western Libraries switched to LibAnswers, but after almost a year, it is an added bonus. As of the publication of this article, IRS is the only department currently answering questions routed through LibAnswers, but due to the flexibility of LibAnswers, this may change in the future.

There are many directions that Western Libraries, and other academic libraries using similar systems, might go in the future with library-wide reference statistics collection. It will be valuable internally for understanding the work done by different departments. Further comparative scholarship is needed to better understand the role different departments play in helping patrons find the answers they seek. As more libraries build a body of reference data this could easily become a reality and that information can be put to use in order to develop more responsive service models. Perhaps even more compelling, in a time of rapid change and budget realignments, is that the data collected will provide evidence to university administrators for the value and instructional role that libraries play.

\section{References}

Aguilar, P., Keating, K. \& Swanback, S. (2010), "Click it, no more tick it: online reference statistics", Reference Librarian, Vol. 51 No. 4, pp. 290-299. 
Garrison, J.S. (2010), "Making reference service count: collecting and using reference service statistics to make a difference", Reference Librarian, Vol. 51 No.3, pp. 202-211.

Henry, D.B. and Neville, T.M. (2008), "Testing classification systems for reference questions", Reference \& User Services Quarterly, Vol. 47 No. 4, pp. 364-373.

Jordan, E. (2008), "LibStats: an open source online tool for collecting and reporting on statistics in an academic library", Performance Measurement \& Metrics, Vol. 9 No. 1, pp. 18-25.

Krikelas, J. (1966), "Library statistics and the measurement of library services", ALA Bulletin, Vol. 60 No. 5, pp. 494-499.

Logan, F.F. (2009), “A brief history of reference assessment: no easy solutions”, Reference Librarian, Vol. 50 No. 3, pp. 225-233.

Meserve, H.C., Belanger, S.E., Bowlby, J. and Rosenblum, L. (2009), "Developing a model for reference research statistics", Reference \& User Services Quarterly, Vol. 48 No. 3, pp.247-258.

Murgai, S.R., (2006), "Reference use statistics: statistical sampling method works", Southeastern Librarian, Vol. 54 No. 1, pp. 45-57.

Novotny, E. (2002), Reference Service Statistics \& Assessment, Washington, DC: Association of College and Research Libraries Office of Leadership and Management Services, available at: http://www.arl.org/bm doc/spec268web.pdf (accessed December 21, 2011).

Rothstein, S. (1964), "The measurement and evaluation of reference service", Library Trends, Vol. 12 No. 3 , pp. 456-472.

Smith, D.E. (1984), "Customized reference statistics programs”, American Libraries, Vol. 15 No. 3, p. 179.

Smith, M.M. (2006), “A tool for all places: a web-based reference statistics system”, Reference Services Review, Vol. 34 No. 2, pp. 298-315.

Warner, D.G. (2002), "A new classification for reference statistics.” Reference and User Services Quarterly, Vol. 41 No.1, pp. 51-55. 